\title{
INFORMATION ASYMMETRY IN INSURANCE FIRMS AND SUPERVISORY INSTITUTIONS RELATIONS: PROBLEMS, CONSEQUENCES AND REMEDIES ${ }^{1}$
}

The study presents information asymmetry characteristics in a relation between supervision institution and insurance firm, discusses reasons for this phenomenon occurring, analyses the possible effects for individual insurance firms and the entire market and also indicates the possibilities and methods for eliminating its negative consequences.

Due to the fact that a supervisory on institution has access to all information regarding an insurance firm under assessment, information asymmetry in the relation between a supervisory authority and an insurance company, by definition, should not take place. However, the performed research into this phenomenon indicates that some of its symptoms can be observed, which results from imperfections ingrained in the information itself, from the cognitive limitations of supervisory institutions staff (decision makers), as well as the indirect implementation, by a supervisory institution, of the information disclosed by insurance firms on a voluntary basis. The consequences of information asymmetry may become the reason for an improperly performed assessment by the supervision authority and may influence the decisions made.

The performed analysis also puts an emphasis on the fact that classically described information asymmetry effects, such as adverse selection and moral hazard, in cases of asymmetry occurrence in the relations between a supervisory institution and an insurance company, should be supplemented by a costly verification of the current situation (collecting information and its credibility verification) which, depending on the scale, is significant for supervisory authorities in the process of the performed assessment and in taking due decisions, as well as for the proper allocation of the resources at the disposal of insurance institutions and also for the correct functioning of the entire insurance market.

Each area of information asymmetry, in relations between a supervision institution and an insurance firm, generates a different type of protection possibilities against its occurrence, its reduced scope and for minimizing its effects, which has also been discussed in the study. Due to the fact that legal regulations and information submission arrangements are not capable of eliminating all information limitations for asymmetry occurrence to be correctly identified, it is necessary to keep monitoring all information processes taking place in relations between a supervision institution and an insurance firm. An indispensable condition for eliminating the limited capacity in recognizing insurance companies' attributes by supervision authorities, is studying the influence of all new regulations and researching the phenomena influencing the course of the supervisory processes. However, the fact that a different (larger) information scope is available for a supervisory institution does not necessarily have to influence the decisions made by this institution.

Keywords: information, information asymmetry, insurance supervision

DOI: $10.15611 /$ aoe.2014.2.07

\footnotetext{
* Department of Finance and Accounting, Wroclaw University of Economics

${ }^{1}$ The project was financed with the means from the National Science Centre.
} 


\section{INTRODUCTION}

The primary manifestations of public intervention in the insurance market are represented for example by the top-down control of particular rules referring to its functioning, rationalization and coordination of certain activities, or appointing institutions performing supervision over entities functioning in the market, including mainly insurance institutions. The purpose of public authorities intervention, by means of the public supervision authority ${ }^{2}$, is to introduce adequate means which guarantee insurance institutions' solvency, or to minimize disturbances and losses resulting from their insolvency, which is manifested by the protection of insurance institutions' clients (protection against any potential loss of money), as well as the protection of the overall insurance market. Such interference may also refer to the provision of equal access to information for all interested parties.

In the case of insurance market participants, the issues of symmetrical (equal) access to information, or just the opposite - information asymmetry - may be analyzed in two dimensions: an insurance institution-client relation. and a supervision authority-insurance institution relation. The first case has been well recognized and frequently described. However, the second one, i.e. asymmetry in relations between the supervision authority and an insurance institution has not been analysed practically. In line with the implementation of public objectives, which are supposed to guarantee the normal course of public life, the legislation in force has been constructed in such a manner that the appointed public supervision authority has access to all the information which may turn out to be indispensable in the process of performance assessment. Owing to the assigned tasks and competencies, it is also privileged in accessing all the necessary information and holds a "superior" position in relation to the supervised entities. This means that theoretically the phenomenon of information asymmetry, on the part of a supervision authority, should not occur. Information asymmetry, however, in relations between the supervision authority and the supervised entities, caused by information imperfections and the limited rationality of the decision maker, constituted one of the components responsible for the financial crisis build-up mechanism in the U.S. market in 2007, when financial supervision which used information originating from direct

\footnotetext{
2 In a further part of the study the "state supervision authority" will be referred to as the "supervision authority".
} 
assessment, turned out to be "helpless" (Eichengreen 2008, p. 1). Also the supporting institutions and those participating in an indirect performance assessment (auditors who approved of accounting manipulations by investment banks, clients, rating agencies), ignored certain crucial information or became susceptible to opportunities of the voluntarily disclosed information manipulations (Bordo 2008, p. 3). Owing to the fact that the surrounding entities did not notice the danger in due time, this also affected the supervision authorities which missed the relevant information and therefore the market assessment (indirect assessment) results did not provide grounds for initiating supervisory operations. The functioning, prior to the crisis, doctrine of "light regulatory touch" turned out to be inadequate and resulted in the decreasing transparency of the financial markets and, in consequence, stimulated the crisis which, to a great extent, owed its scale to the insufficient information about the actual standing of particular financial institutions (Sławiński 2010).

The thesis according to which at the level of relations between an insurance supervision authority and an insurance firm, even though information asymmetry is present to a limited extent, became the background for the discussed problem's analysis. The need to undertake research in the area of information asymmetry, underlying the relations occurring between an insurance firm and a supervision authority, defined the main goal of the study focused on this phenomenon's analysis and description, covering the characteristics of the reasons for asymmetry, the analysis of its possible results and the identification of the methods and strategies aimed at the reduction of asymmetry probability occurrence, as well as minimizing its negative effects. The supplementary objective refers to the problem of the assessment of insurance firms supervision, ${ }^{3}$ in the course of which information asymmetry represents one of the possible reasons responsible for an incorrectly performed assessment by a supervision institution, and hence influencing the decisions made.

\footnotetext{
${ }^{3}$ Performance assessment should be understood as an assessment performed by the public supervision authority during the monitoring and controlling phase of the existing situation based on information provided in line with the legislation in force (after such an assessment the second phase of supervision process takes place - the possibility of exerting due impact resulting from the appropriate powers).
} 


\section{THE ESSENCE OF INFORMATION ASYMMETRY}

The phenomenon defined as information asymmetry consists in the fact that the scope of information at the disposal of the transaction parties is different and refers to the uneven distribution of the acquired information (Polański, Pietrzak, Woźniak 2008, p. 25). In economics the phenomenon of information asymmetry is not a new idea and has already been frequently described. It was already in the 19th century when the first studies discussing information access were published. The economist Friedrich A. von Hayek is considered to be the precursor who recognized the role of knowledge and information in the economy, as well as the author of the thesis that incomplete information results in market inefficiency and disturbance. The theory of information asymmetry was developed in the 1960s and 1970s, and the concept of "information asymmetry" was introduced in economics by J. A. Mirrlees who was awarded the Nobel Prize in 1996 for his research on the relations between private enterprises and the State government in the context of information asymmetry. It was also in 1996 that W. Vickrey received the Nobel Price for his input in developing the theory underlying functioning in the conditions when collecting full information about the market turns out to be impossible (Blajer-Gołębiewska 2007, p. 58). One of the contemporary information asymmetry definitions - "some market participants are better informed" - was presented by M. Spence, who in his studies analysed the problem of information uncertainty between buyers and sellers (or employers and employees) meeting in the market. He also analysed the problems of the methods for another party attributing recognition in conditions of uncertain information facilitating overcoming competition barriers (Spence 1973, pp. 355-374). The effects of information asymmetry occurrence, which result in "disturbances for transacting entities' economic account and therefore give way to sub-optimal economic decisions in micro scale, while in the macro scale result in the ineffective (in the Pareto sense) allocation of resources”, were described by J. Stiglitz. In the latter meaning, information asymmetry is one of the reasons underlying market failure, i.e. a situation when the market mechanism does not ensure the effective implementation of resources (Sloman 2001, p. 232) and the total absence of information about a particular phenomenon, discussed by G. Akerlof, can even result in market disappearance (Akerlof 1970, p. 498).

The phrase "information asymmetry" can be used as the synonym for such concepts as "unclear information" or "the absence of information transparency”. Relevant efforts are undertaken in many markets to minimize 
information asymmetry, if it is possible, or to ensure equal access to information for all market participants. One such activity is the identification of strict information obligations (especially with reference to the financial market) following which entities functioning on this market have to supply a lot of current information to the market characterized by proper quality and referring to their operations (Izquierdo S. S., Izquierdo L. R., 2007, pp. 858867). In spite of the above efforts, there still occur undesirable external effects resulting from "unclear information", which have been defined in the contract theory as adverse selection and moral hazard (Mas-Colell, Whinston, Green 1995, p. 11). The situation in which one party is in possession of more information or is in a privileged information position in relation to another party, can also be referred to the context of relations and interdependencies between the public supervision authority and the enterprises subject to supervision in a given market (insurance firms).

\section{INFORMATION REGARDING THE SUPERVISION AUTHORITY-INSURANCE FIRM RELATION}

As has already been mentioned, information asymmetry refers to a situation when one of the parties is privileged in certain information access and the range of information at the disposal of the transaction partners is different and unevenly distributed. In the case of transactions which refer to a commodity or a service, the subject undergoing transaction is easy to analyze and assess, however in cases of the supervision authority-insurance firm relation it is the information which constitutes the subject of the "transaction". It can refer to information about: the financial situation of an insurance institution, meeting due obligations regarding customers, fulfilling regulatory requirements, etc. Such information, provided for the purposes of the supervision authorities, facilitates the assessment of an insurance institution's performance and provides the background for making appropriate decisions.

The supervision authorities which control insurance institutions enjoy a privileged situation regarding the available information. According to the legal regulations of almost every country, the supervision authority has the right to demand all the information indispensable for supervision purposes and necessary for both performance and solvency assessment (e.g. regarding the applied valuation principles, in order to define the solvency situation, the encountered types of risk, risk management systems and also capital 
structure, capital needs and capital management, etc. $)^{4}$. This information is supposed to facilitate taking all the appropriate decisions resulting from the performed supervisory rights and duties.

A supervision authority also has the right to define the nature, scope and format of indispensable information obtained directly from insurance firms, as well as the right to be provided with all information referring to agreements entered into by agents and those signed with third parties, or even require information to be delivered by outside experts (accounting auditors and statutory actuaries). The required information may refer to past, present and future situations, or include both quality and quantity components, while data covered by due information may originate from both internal or external sources (Directive 2009/138/EU, Article 35).

A supervision authority may also expect to be provided with information on the level of insurance groups, or financial conglomerates, which was even strengthened in the European Union by appointing new supervision authorities to control financial markets (Directive 2010/78/EU). Additional supervision over financial conglomerate entities, as well as supervision over a group, facilitate the relevant authorities in controlling a single insurance firm in order to perform a better justified assessment of its operations (Dreher 2009, p. 17).

In order to ensure effective supervision over the functions or types of activities recommended within the framework of outsourcing, the supervision authorities were also provided with access rights, regardless of whether the contractor is a regulated unit or not, to all substantial information (data) at the disposal of this contractor, as well as the right to conduct an on-site inspection - the supervision authority should even be informed prior to outsourcing basic or key functions, or types of operations (Directive 2009/138/EU, Article 34 (2-7)).

If a supervised entity does not meet its obligations as regards information access provision and obtaining, by the supervision authority, all the crucial information for fulfilling its goals will turn out to be impossible, then - where appropriate - apart from taking court action, information may be obtained using enforcement measures (Directive 2009/138/EU, Article 34 (8)).

\footnotetext{
${ }^{4}$ The scope of the information indispensable for the assessment of a certain entity is defined by individual regulations in force in a given country, however, they are based on certain recommendations and standards prepared, among others, by the IASB (International Accounting Standards Board) - basic reporting and the IAIS (International Association of Insurance Supervisors) - reporting for supervision purposes.
} 
Apart from general rules defining information usefulness such as accuracy, timeliness, completeness and adequacy (Davenport 1989, p. 68-94), there are also recommended rules to be followed in the course of useful information provision or even legislation defining principles for preparing and transferring information meeting the requirement of usefulness. At this point, it seems justifiable to refer to the conceptual framework of financial reporting prepared by the IASB (IFSR, Conceptual Framework for Financial Reporting) and the records included in the Solvency II directive (Directive 2009/138/EU) dedicated to this problem. In the first case, the information is useful if it features two fundamental qualities, i.e. relevance and faithful presentation. To supplement these fundamental qualities there are also enhancing ones: comparability, verifiability, timeliness, understandability, which allow for distinguishing more useful information from less useful and result in the fact that the relevant and faithful presentation of actual information is characterized by higher usefulness. In the second case, the information generated for supervision purposes, in order to present a particular informative value, should (Directive 2009/138/EU, Article 35): reflect the nature, scale and complexity of a given entity functioning (and especially the risk typical for its operations), be available, full in all crucial respects and comparable, as well as coherent in the course of time (continuity of transferred information) and also understandable, relevant and credible.

Having analysed the above presented rules, principles and legal requirements related to generating and transferring information for the purposes of the supervision authorities, it can be observed that in the case of the supervision authority-insurance firm relation, when considering "information imbalance of the interested parties", it is the insurance company which represents the less informed party, since it is capable of collecting only basic information about the supervision authority. This is obviously sufficient and there is no substantive justification for collecting a more extensive range of it. On the other hand, a supervision authority has the right, is capable of, and does collect all the possible information about the situation of an insurance firm in order to be able, in the course of the conducted supervision process and at the stage of collecting information, to perform the proper assessment of the due operations and as a result, be provided with all the necessary tools to make the correct decisions. 


\section{INFORMATION ASYMMETRY IN THE SUPERVISION AUTHORITY - INSURANCE FIRM RELATION}

Due to the fact that a supervision authority represents the party which is provided access to all possible information in the relation between itself and an insurance company, it can be stated that information asymmetry does occur in this situation. The insurance firm is obviously at a disadvantaged position here, while an opposite situation, i.e. when a supervision authority could find itself in depleted information circumstances seems hard to imagine. This should not take place anyway, however, as it has initially been mentioned, some symptoms of asymmetry may be indeed identified:

- asymmetry which results from the imperfections of information itself,

- asymmetry which results from the cognitive and analytical limitations of the assessment authors (supervision authority workers),

- asymmetry which results from the possibility of manipulating information provided by insurance institutions and referring to this information which is made available for the public and is of a voluntary rather than an obligatory nature.

In a way these areas overlap, however, distinguishing them is significant in the context of undertaking the possible activities necessary to eliminate the negative effects of information asymmetry.

The first area of information asymmetry, in relations between a supervision authority and an insurance firm, refers to information asymmetry resulting from imperfections in the information itself. Such information imperfections are influenced by many factors, not all of which refer to supervision authorities. For example, the problem of costs incurred in obtaining information does not pose any barrier for a supervision authority in its decision-making process, since all expenses for preparing information are covered by insurance institutions. Possible imperfections in this area may result from the cost-benefit relation, i.e. when the advantages from preparing information could be smaller than the cost of obtaining them - in such cases collecting information turns out to be ineffective and imposes functioning in conditions of ignorance (Forlicz 2001, pp. 52-64). Similarly, access to an extensive range of information regulated by legislation results in the fact that the information provided for the supervision authorities is complete by definition. However, information imperfections may be influenced by the 
high changeability of the environment and the resulting difficulties in processing necessary information (Samuelson, Nordhaus 1996, p. 193), which refers to all stakeholders (also supervision authority workers). This can result in using imperfect information which not only is inadequate, imprecise, but also outdated (Forlicz 2008, p. 24). Imperfect information may also bring about its incorrect interpretation, as well as deny the possibilities for making effective forecasts. Even though it is true that the extensive powers of the supervision authorities, regarding information access, by assumption rule out its imperfections, yet these are just assumptions, while the information characterized by limited cognitive value (failing to meet the usefulness requirement) may become the reason for performing an incorrect assessment.

The second area of information asymmetry in relations between a supervision authority and an insurance institution, refers to asymmetry resulting from cognitive and analytical limitations of an assessing institution. The idealization of assumptions characterizing the profile of a decision-making entity assumes that it does not have any cognitive limitations and all decision-makers are fully rational and make decisions in the conditions of ideal and perfect access to information (Weirich 2004, pp. 45-49). In real life, at each stage of the decision-making process an entity struggles against certain limitations resulting from its environmental and internal situation - information is neither full, nor is its transfer is performed in a perfect way, nor is it always true (Stiglitz 2004, pp. 80-83). This emphasizes the presented above aspect of information imperfections, while the stage of collecting information featuring adequate quality, its processing, interpretation and implementation is particularly prone to mistakes resulting from the cognitive and analytical limitations of an assessing authority (selective perception, inadequate education, time constraints, accepting previous assumptions, missed understanding of information, very narrow specialization).

It is indeed true, that the cognitive and analytical limitations of the assessing authority should not occur at all, still "the individual may operate under an illusion that he is more informed than he actually is; he may be ignorant but not aware that he is" (p. 183, Buchanan) which, in general, (with reference to information processes) may result from the incorrect analysis of information needs, the false review of the collected information, its processing, interpretation and implementation. Properly conducted information processes influence, to a great extent, the cognitive value of the performed assessment. Using incomplete information, or carelessly verified 
data, can result in wrong decisions and false conclusions which, in consequence, may present a distorted image of an assessed entity and that is obviously translated into the high probability of making incorrect decisions.

The possibility of meta-information and para-information asymmetry occurrence resulting from the cognitive limitations of decision-makers, is especially noticeable when transforming the core concept of insurance supervision from the model oriented on the quantitative assessment of financial measures (Solvency I) to a supervisory model covering (apart from financial parameters) also the quality oriented aspects. The individualism present in Solvency II, regarding both the analysis and assessment of an insurance firm's performance, as well as difficulties in the proper interpretation of the acquired information, further intensify the limited rationality of a decision maker. The most representative example illustrating the possibility of information asymmetry occurrence is that of regulations which adjust the size of guarantee capital to an individual risk profile of operations performed by an insurance company. In the first Solvency II pillar, this mainly refers to an insurance institution internal models, the final construction of which, their implementation and the capacity of calculating capital requirements on their basis, does depend on the control performed and the approval issued by a supervision authority. Its workers analyze the relation between the particular model's adequacy and the most significant risks, and also the overall risk of an insurance company. Acceptance is granted only when a positive result is obtained. At this level, information asymmetry may appear as the result of the decision-makers' limited rationality, since performing an assessment appropriate to the level of complexity characteristic for models used by insurance institutions is not easy and suffers imperfections typical for any quality focused assessment ${ }^{5}$, as well as deficiencies resulting from human attitudes (overestimation of one's analytical skills, or overrating individual capacity for making a correct assessment). Both properties may bring about an improper interpretation of available information, which influences the phase of performance assessment in the course of the conducted supervision process. The assessment presented by the supervision authorities which implements descriptive parameters, not just absolute figures, has the potential of

${ }^{5}$ Qualitative assessment limitations are as follows: subjective nature of an assessment performed, verification in relation to idealistic initial assumptions (adjustment to patterns) taking advantage of individual experiences, freedom of interpretation, broad or narrow interpretation. 
reflecting the quality of the insurance institution's operations (Kurek 2009, p. 76). However, it brings the risk of the improper interpretation of the obtained information and therefore may result in making wrong decisions. At this point it should be emphasized that with reference to quantitative supervision dogma (Solvency I), information asymmetry caused by the limited rationality on the part of a decision maker also did occur, however, to a lesser extent since it was the information about meeting quantitative standards which became the underlying and basic reason for making due decisions, without the need for descriptive (qualitative) parameters assessment, while the risk of information asymmetry in relation between an insurance company and the supervision authority, resulting from the wrong interpretation of the available information, was much lower.

In accordance with the concept of a supervision authority functioning in conditions of qualitative supervision dogma, it is also an insurance company's own capacity for risk assessment which determines the firm grounds for its functioning, and also its individual ability to evaluate risk, to manage it skilfully and to forecast future threads. Therefore in the second Solvency II pillar, apart from an insurance company's scope of operations and risk profile, the focus is also on investigating the processes of risk management systems implementation, usage and control by a supervision authority. These areas of insurance institutions' functioning become the subject of supervision authorities' investigation, processing, interpretation and assessment. Against this particular background, the elements determining information asymmetry, as a consequence of cognitive and analytical limitations featuring assessing authorities, do occur. These are the components influenced by the evaluation of procedures applied in a company (high individualism of assessment, absence of standards, difficulties in preparing assessment methodology), potentially over extensive generalizations of qualitative assessment criteria (allowing for a broad and narrow interpretation in a given insurance institution), or incorrect information interpretation resulting from a passive approach presented by the assessing authority.

The third area of information asymmetry, in relations between a supervision authority and an insurance institution, refers to asymmetry resulting from the capacity for manipulating publicly disclosed information of a voluntary nature by insurance firms. The possibility of such informational absence of transparency is related to the diversity of information sources available to the supervision authorities, as well as the absence of both the necessity and possibility for some verification of 
information accuracy. In the course of the performed supervision processes, the relevant authority focuses on an information source dedicated to it (reporting for supervision purposes), however it may also take advantage of the following information sources:

- information of an obligatory nature, provided for the public by the insurance companies, the credibility of which should be primarily guaranteed by the supervision authority,

- information provided for the public by the insurance companies on a voluntary basis.

Taking advantage, by the supervision authorities, of different information sources facilitating assessment of insurance companies performance, allows for distinguishing both direct performance assessment (using reporting for supervision purposes) and indirect performance assessment (using publicly disclosed information). Distinguishing an intermediate assessment results from that fact that although it is performed by a public supervision authority, the assessment itself is made based on signals coming from an insurance company environment (market performance assessment results), and also from inside, based on information provided to the public on an obligatory and voluntary basis (company assessment by its owners). It is only at the stage of introducing performance corrections (having an impact on the decisions made by insurance firms) that administrative tools, typical for state supervision, are applied (Jackowicz 2004, pp. 15-24). The crucial input into the supervision process is made by taking advantage of both the obligatory and voluntary information disclosed to the public in order to support direct assessment. Theoretically, in both cases it is possible to suffer information manipulations ${ }^{6}$ resulting in information asymmetry, however such a danger does occur only in the second case (publicly disclosed information, but in a voluntary manner).

In cases of public information of an obligatory nature, asymmetry of information will not, by assumption, take place since it is the State that secures the obligation of its publishing and guarantees the reliability of the generated information. For this reason, in order to meet the commitment of presenting it to stakeholders and to verify its accuracy, special institutions were established (auditors, supervision authorities) and adequate regulations

\footnotetext{
${ }^{6}$ Manipulation is understood, in this case, as informing and misinforming stakeholders by means of skilful selection and presentation of both positive and negative information, or disregarding some information influencing erroneous identification, or impossibility to verify the reality which particular information refers to.
} 
were specified to confirm the information authenticity (information standards). The legally regulated scope of information prevents manipulating information and controlling its recipients (information has to present the specified quality and properties which decide about its usefulness for the recipients) and therefore the danger of an ambiguous interpretation of information by its addressees is prevented and the signals coming from the supervision authorities (indirect assessment) will not put a particular recipient in the position of a less informed entity.

In cases of publicly provided voluntary information (indirect assessment), information asymmetry may be present. Even though according to general management rules it is true that in order to be able to control information recipients in an effective way, correct information is not necessary at all - it is enough that the individuals to be influenced did not have any opportunity to verify this information source - which already brings about the risk of information asymmetry, still the more important issue at this point is the content of the information being actually provided. The information disclosed on a voluntary basis is generated by insurance institutions following their own initiative and therefore no obligation occurs to meet certain standards or provide them in any specific form. For this reason insurance companies are capable of manipulating such information and, as a result, may skilfully misinform stakeholders by resorting to a subjective selection and presentation of both positive or negative information (or even disregarding some of them), which allows for influencing the individuals responsible for performing due assessments, as well as the relevant decision makers (Marcinkowska 2000, p. 152). From a formal perspective, the information itself cannot be falsified or modified at all and manipulation may manifest itself in an insurance institution generating or providing information in a purposeful manner and presenting it in such a way that its user or recipient will fail to interpret correctly the reality described by means of such information. It is hard to protect oneself against manipulation taking advantage of a selected information scope, since it is the user himself/herself who should be blamed for its misinterpretation, or the wrong evaluation of information generating system (Oleński 2006, pp. 75-76). At this stage the threat occurs in both asymmetry layers, i.e. stakeholders will not know how to interpret the generated information and for what reason this particular information has been generated, or to what extent it may be regarded as credible. 


\section{INFORMATION ASYMMETRY EFFECTS IN THE SUPERVISION AUTHORITY-INSURANCE FIRM RELATION}

In the classical perspective, the negative effects of information asymmetry occur both during the process prior to signing an agreement (so called ex ante phase) and after signing it (ex post phase). The better informed party of an agreement is exposed to the temptation of improper behaviour, both in the first and the second contract phase. During the ex ante phase information asymmetry results in problems of adverse selection, while in the ex post phase the risk of moral hazard is present (Mishkin 2002, pp. 251273). Moral hazard and adverse selection represent problems which occur as a result of the conflict of interests between the transaction parties and are observed as an insurance agency cost brought about by this conflict (Jensen, Meckling 1976, pp. 305-360). Part of the costs covered by an agency are also those resulting from the need to cover the expenses associated with due verification (acquiring information and its credibility verification), i.e. transaction costs. The same phenomena (effects of information asymmetry) obviously take place also in the relations between the supervision authority and an insurance institution, however, their importance is different and the significance of particular effects is also spread differently.

The existing conflict of interests, and agency costs associated with it, result from a simple relation - the supervision authority wishes to obtain the most comprehensive information while an insurance institution wishes to hand over such information which presents it in the best possible perspective. Since such asymmetry may result from the imperfect nature of the information itself, or from the cognitive and analytical limitations represented by the legal advisors employed by the supervision authority, or from manipulating the voluntarily provided information by insurance companies, the supervision authority will aim at obtaining full information and that involves the expensive verification of the status quo, which allows to qualify this effect at the same level as adverse selection and moral hazard.

Therefore it seems obvious that insurance institutions, in order to be best assessed by supervision authorities, try to provide "the best" information and disregard the negative one. However, as has already been discussed, owing to a supervision authority's broad access to all possible information regarding the supervised entities, adverse selection will not occur in cases of direct supervisory assessment. Such an effect of information asymmetry may be present and turn out to be significant if indirect supervisory assessment is performed. It is possible that an insurance company provides (discloses to 
the public) certain information deliberately, since from the supervision process perspective it does not matter at all, however, it is announced in such a manner that it does influence the decisions made by stakeholders. Based on such information, stakeholders make decisions and their choices, and if their assumptions are wrong (owing to the incorrect information they have obtained), then the signals coming from clients (as an indirect assessment of the activities) are received by the supervision authorities and may result in an incorrectly performed assessment, which will also result in making wrong decisions.

Due to the absence of full information or its incorrect interpretation, the supervision authorities are also prone to making incorrect choices (decisions made) as a result of the performed quality evaluation and more specifically information interpretation incurs the risk of taking different attitudes by the supervision authority - either moderate or strict. In the first case (moderate attitude taken by a supervision authority), it stimulates the occurrence of moral hazard on the part of insurance institutions which, owing to the fact that their position and financial situation were incorrectly assessed (overoptimistically), may become involved in making risky decisions and not being afraid of sanctions to be imposed by the supervision authorities. An over-optimistic assessment of an insurance company's risk profile can, in fact, result in threats to insurance services clients, which may even pass unnoticed by a supervision authority. In cases when a supervision authority follows an "overly strict" attitude, information asymmetry can result in supervisory arbitrage. Such a phenomenon refers to a situation when insurance institutions may choose their operations location based on how "moderately" or "strictly" the supervision is performed. Such an environment reduces competition and constitutes a model example of information asymmetry becoming one of the reasons for market failure, in which market mechanisms do not provide the optimal allocation of resources. Moral hazard can also refer to supervision authorities which, based on their dominant position, do not take full advantage of the priorly obtained information and require its additional provision, claiming that their currently available information set is insufficient. In such situations, insurance companies have to consider the fact that the supervision authority may keep requiring more and more updated and detailed information, which means additional costs of their generation.

Transaction costs as one of information asymmetry's effects can be divided into those related to information collecting efforts and those which refer to verification of their correctness. In both cases, less knowledge about 
a certain phenomenon (process) results in more risk and, in consequence, the need to use more time and effort to safeguard oneself against the unknown (Amundson 2005, pp. 30-31). Even though supervision authorities do not cover the costs related to obtaining information (they are covered by insurance institutions which generate information for the supervision authority's purposes), yet those referring to verification of the information correctness are viewed as the significant, negative result of asymmetry. Verification of information correctness, its constant updating, making decisions about the current state of knowledge (by performing controls), monitoring, processing and the ongoing interpretation of information, depending on the changing circumstances, results in covering significant and necessary expenses, which are supposed to reduce the asymmetry and allow for the reduction of information related limitations.

\section{THE POSSIBILITIES OF SUPERVISION AUTHORITIES PROTECTION AGAINST INFORMATION ASYMMETRY}

The functioning of the market mechanism aimed at "repairing" inefficiencies brought about by information asymmetry is, indeed, possible in the case of market actors (in the insurance market it refers to the clientinsurance firm relation). However, in the case of an insurance companysupervision authority relation, market rules do not operate and the full efficiency of supervision authority activities does require "perfect" information facilitating the correct assessment of each area active in an insurance institution's performance, the lack of analytical assessment limitations and the application of solutions preventing insurance companies from manipulating voluntarily disclosed information.

Possible preventive measures reducing probable asymmetry resulting from imperfections of the acquired information may refer to obtaining the largest possible information set, as well as improvements in its processing and verification. The resources available to supervision authorities in this matter are as follows (Kurek 2010a, p. 951):

- obtaining information submitted within the framework of information obligations imposed on an insurance firm (statements, reports),

- the acceptance (approval) of the presented information after its content verification, 
- collecting information referring to company organization and functioning (inspections on site) and related to the market environment of a given company,

- the analysis of the obtained information (analysis of information from insurance institutions, market analyses),

- defining the nature, format and scope of the required information,

- the right to impose the obligation of submitting additional information and data,

- the right to agree upon the scope of information.

Self-selection is another method for dealing with information asymmetry. This refers to a situation when a less informed party (supervision authority) designs requirements regarding information to be submitted by the party having information superiority (insurance institution) so that it can selfselect crucial information. A good example may be (and in fact is) the requirement made by the supervision authority to submit a self-assessment conducted by an insurance company. The self-assessment of risk and liquidity (e.g. provided by Solvency II ORSA ${ }^{7}$ ) is performed for its own decision-making purposes and is supposed to assist insurance institutions in identifying decision-specific situations and making the right choices in both the short- and long-term perspective. The effects of each conducted assessment should also be made available for a supervision authority as a supplement to the basic information. An insurance institution (as a better informed party) decides which risks match its profile - and being aware that the performed self-assessment is to be verified by the supervision authority will provide it with all the information (both good and bad). In this way the supervision authority gains information which is not part of the standard, legally enforced scope of information, and the insurance firm itself indicates the information to which a supervision authority would not pay attention to in the regular supervision process by disregarding it or treating it as irrelevant. Such an attitude may turn out to be effective if a supervision authority makes full use of the instrument it was offered, while the conducted performance assessment becomes the variable to which a better

${ }^{7}$ Own Risk and Solvency Assessment - ORSA as the tool within the framework of risk management system, is provided by Solvency II. This tool requires an insurance firm to perform proper assessment of its own risk, both short and long-term, as well as the amount of its own financial resources indispensable for covering it. Self-assessment should be conducted on a regular basis (once a year, at the minimum) and should also be done immediately after the occurrence of all significant changes influencing the risk profile (Kraśniewska, Pawelec 2009, p. 5). 
informed party (insurance firm) is sensitive relative to its risk profile. In this way a supervision authority extends its information base which is indispensable for conducting a correct performance assessment and the risk of the absence of information transparency decreases.

With reference to asymmetry resulting from cognitive and analytical limitations, evaluating suggestions for activities aimed at reducing its effects primarily refer to the modification of the requirements related to the information systems and models used in generating information (especially risk quantification models, valuation models, etc.), as well as their assessment by supervision institutions in line with changing trends, market determinants and the complexity level of the supervised entities' operations. As far as the information system participants are concerned, such reducing activities can cover the following: training for staff and employing new workers, developing assessment methodology, setting standards (including the right to individualism), unification of assessment procedures, etc. It covers all the possible activities aimed at minimizing, or even eliminating, cognitive limitations for supervision workers and facilitates undertaking "perfectly" rational decisions. In case of any doubts it is also possible to commission an expertise or reports and assessments from independent experts who present information regarding the financial situation in an objectively verifiable way, which helps supervision authority workers in performing due assessments. In cases of insurance companies involved in cross-border and cross-sector activities minimizing negative consequences of asymmetry, this is possible owing to information exchange between different safety network institutions by means of transferring information between supervisors originating from different countries and also as the result of their cooperation in exchanging experiences and improving both the assessment methods and tools. In the latter context the reason for the "extensive" transparency of insurance institutions is also the disclosure, by supervision institutions, of the performed assessments referring to insurance companies, while as a form of reducing information imperfections it could also turn out to be useful to disclose the rules followed in the process of exercising supervision (public control of the applied supervisory practices). This should guarantee the transparency of supervision authorities functioning in particular EU Member States, and by means of strengthening their responsibility could reduce the possibility of regulatory and supervisory arbitrage exploited by insurance firms.

On the other hand, it turns out to be difficult to indicate solutions referring to minimizing the effects of asymmetry resulting from the possibilities of manipulating publicly provided information of a voluntary 
nature (a supervision authority takes advantage of signals from clients based on voluntarily generated information - indirect performance assessment). The average information recipient and user (not a supervision authority which represents a specialized information recipient) does not typically verify the obtained information. It is accepted as useful or disregarded as useless. While assessing whether particular information reflects the reality, the average user simply verifies the information source's credibility, provided such information is available (Oleński 2006, p. 73). Theoretically, a useful solution would be one preventing insurance companies from publishing unverified information from the relevant institutions (e.g. supervision authorities) and could reduce the information asymmetry. Obviously, such a solution is unfounded and inapplicable in practice. Insurance firms (and others) are obliged to provide true information and when this requirement is not met the disadvantaged party (the victim), as the result of untrue or falsified information, has the right to demand compensation. Adequate preventive activities in this matter may be conducted by governmental and non-governmental organizations and institutions which verify information truthfulness (offices of competition and consumer protection, offices of fair trading, ombudsman's offices insurance ombudsman, consumer ombudsman, consumer advocate etc.). Assessments of insurance firms can also be performed by rating agencies, creditors, market analysts, environmental organizations or even competitors who, in the context of market information efficiency, exert an impact on market discipline translated into the possibility of using market signals by supervision institutions.

Obviously some distance and verification performed by supervision authorities regarding information coming from the environment (indirect assessment), offer an opportunity to minimize threats related to information asymmetry, while credible "signalling" and "giving signs" (Varian 1997, pp. 633-634) represent methods aimed at reducing the absence of information transparency and possible to apply by an insurance company, in the framework of which great significance should be assigned to internal auditors and internal audit systems. An insurance company's reputation, accompanied by the generally understood honesty and solidarity in meeting contractual terms and conditions, as well as due obligations, is a sign for a supervision institution which facilitates verifying the credibility of information coming from the market and allows for its assessment by constituting the background to take appropriate decisions. 
With reference to asymmetry resulting from cognitive limitations and assessing analytical ones, as well as asymmetry related to voluntarily disclosed information, a very important role is played by auditors, institutions providing assurance services, actuaries as well as other independent individuals and entities, the activities of which facilitate information verification and its credibility enhancement. This refers to both financial statement audits, reports verification about reserves and technical provisions calculation and also to the confirmation of the credibility of the voluntarily disclosed information.

While the effects of information asymmetry are possible to be reduced and minimized on an individual scale, globally such a situation is perceived completely differently. The Nobel Prize winners quoted in this paper and dealing with information asymmetry, indicate that as a result of wrong decisions a situation may occur in which market mechanisms do not bring about optimal and effective resources allocation (information asymmetry becomes one of the reasons for market failure) and market disturbances may even, in extreme situations, result in the loss of resources (this is indicated as one of the most serious information asymmetry results). Even though in relations between a supervision institution and an insurance firm, market disappearance is certainly not the case, still the key aspect of the problem focuses on changes in the insurance markets functioning system with regard to information asymmetry on the part of supervision institutions. A single case of a "cheating" insurance company, an insufficiently informed supervision institution, or an insurance firm having lower capital requirements than it results from its risk profile in an overall market scale, is not that significant. It is important, however, that with high intensity of nontransparent information the decisions made by supervision authorities do influence the functioning of the entire insurance market by limiting proper relations and may even undermine its functioning stability.

Eliminating the effects of information asymmetry in the relation between a supervision institution and an insurance firm, in the entire market scale, requires profound changes in systemic paradigms according to which these market entities should become subject to stricter regulations regarding, among others, the generated information. These regulations refer to all financial markets, which facilitates effective supervision on a global scale (Heise 2010) and obviously also involve the insurance markets.

The rule, according to which less information is a limitation to greater transparency, is followed by market regulators in the area of assessment performed by supervision authorities in both a direct and indirect manner. 
On the one hand, a systemic change in approach towards assessment (quality and quantity oriented approaches) is observed and insurance institutions face increasing obligations regarding information to be provided for the benefit of supervision authorities while, on the other hand, the scope of information offered publicly and verified by a supervision institution becomes extended, which provides equal access to it for all stakeholders (Kurek 2010b, pp. 340350) and facilitates the supervision authorities in their market assessment results implementation (indirect performance assessment). The conducted transformations cover many areas of the broadly understood information processes, type of channels for information transfer, benefits and costs account of information circulation as well as its quality. A significant example, in this matter, is supervision ${ }^{8}$ of rating agencies operations with, as market institutions which provide processed information regarding insurance companies' performance. Supervising their operations means strengthening those mechanisms which influence the choices made by clients and facilitates the proper assessment of signals received from clients. For the supervision institutions the credibility of assessment presented by the rating agencies results in better conditions for indirect assessment performance, especially in the area of voluntary information generated by insurance companies, which helps make decisions regarding the entire market's functioning and not just within the framework of the supervision processes over individual insurance firms.

\section{FINAL REMARKS}

The imbalance in accessing information is of a multi-faceted nature and can be analyzed on many levels. In cases of supervision institutioninsurance firm relations, one of the crucial issues regarding the proper assessment of an insurance institution's performance process refers to information asymmetry. This situation means that a supervision authority does not have full information about the risk and other aspects of an insurance firm's functioning, and in order to ensure the efficiency of the supervision activities, information has to be transferred and used without any delay, should be made available without any limitations and provide for the reliable assessment of the supervised entities' operations.

${ }^{8}$ European Securities and Markets Authority (ESMA), which was established on 1 January 2011, within its competencies also performs direct supervision over rating agencies. 
Theoretically, the situation of information without transparency, in relations between a supervision institution and an insurance firm should not occur, because of the supervision authority's obvious advantage in its practically unlimited access to all the possible information about an insurance company. However, the imperfectness of the submitted information, the occurrence of cognitive limitations experienced by supervision institution staff (decision makers), as well as the possibilities for manipulating publicly disclosed, by insurance companies, information of a voluntary nature (which influences the indirect performance assessment made by supervision authorities), result in the fact that this phenomenon cannot be entirely eliminated. Information asymmetry does appear in spite of the fact that information sources are clearly defined for the supervision authorities and accessing them is regulated by law. The developed and refined, by many supranational institutions and organizations (IASB, IAIS), framework of information systems for the purposes of supervision institutions has turned out to be insufficient. This situation has not been changed by the EU regulations, nor clarified by specific legislation at national level. Despite the fact that supervision institutions staff, as experts in their field, do have the knowledge indispensable for the proper analysis of available information, the possibility still occurs of its incorrect interpretation, and therefore the application of market assessment results by supervision institutions (indirect performance assessment) may also adversely influence the provided assessment of operations and distort the decision making processes.

The information asymmetry phenomenon, occurring in a supervision institution-insurance firm relation, may turn out to be a threat for the correct assessment of insurance companies' performance, which brings about implications of adverse selection and moral hazard and is also related to the expensive verification of actual status. Depending on the scale, information imbalance effects may turn out to be significant for making the correct decisions by insurance institutions, or for the proper allocation of resources at their disposal and even for the proper functioning of the overall insurance market.

Limiting and minimizing information imbalance is not only possible but, by all means, necessary. In the general perspective, this comes down to providing such conditions for supervision authorities, in their process of the assessment of insurance companies performance, which facilitate conducting such an assessment in a proper and reliable manner (access to high quality information, offer the possibility for creating new information resources, for 
improving qualifications of individuals responsible for performing due assessments, for the verification of market assessment results and reducing possible manipulation by insurance companies regarding voluntarily generated information). It is also of great importance to introduce institutional and organizational solutions aimed at cutting costs related to information generation and covered by insurance institutions, as well as supervision costs resulting from information processing or current status verification while focusing, at the same time, on better compliance with objectives targeted by both parties.

On the scale of the entire insurance (and financial) market, minimizing asymmetry is possible as the result of establishing global and effective regulations as well as efficiently functioning supervision institutions. However, legal regulations and information provision arrangements will never rule out all possible information limitations. It would be quite naive to assume that even in best possible combination of conditions involving all the possible activities aimed at reducing information asymmetry, such a phenomenon will disappear forever. Therefore it is necessary to keep monitoring it as well as to study the influence of all possible new regulations and processes occurring in relations between a supervision institution and an insurance firm, both regarding the possibility of information asymmetry occurrence and opportunities for its possible effects reduction and minimization, so that the capacity to recognize insurance companies' attributes, in their assessment process conducted by supervision institutions, is not in any way limited.

The above presented analysis of both the uncertain and uneven status of submitted and obtained information, which generates circumstances for a supervision institution's functioning in conditions of limited or reduced capacity for recognizing a given insurance firm's attributes, assumes that if a supervision authority had at its disposal different (more extensive) information resources it could undertake different actions. However, supervision institutions always function based on the limited scope of information relevant for them and obtaining more information does not have to mean that their assessment of an insurance firm's performance would be different, and that if they had larger (different) information resources to work on the result of their decision making process would change. 


\section{REFERENCES}

Akerlof, G., The Market for "Lemons": Quality Uncertainty and the Market Mechanism. “The Quarterly Journal of Economics” 1970/84 (3), pp. 488-500.

Amundson, A., Market Impact: Transaction Cost Analysis and the Financial Markets, “Journal of Financial Transformation” No. 13, 2005.

Blajer-Gołębiewska A. Modelowanie niepetnej informacji za pomoca teorii gier [Incomplete Information Modelling by Means of Games Theory] [in:] Kopycińska, D. (ed.) Działania ekonomiczne podmiotów rynkowych [Economic Activities of Market Entities]. Wydawnictwo Katedry Mikroekonomii Uniwersytetu Szczecińskiego, Szczecin, 2007.

Bordo, M. D., An Historical Perspective on the Crisis of 2007-2008, NBER Working Paper No. 14569, National Bureau Of Economic Research, Cambridge, 2008.

Buchanan, J. M., Finanse publiczne w warunkach demokracji [Public Finance in Democratic Process]. PWN, Warszawa, 1997.

Davenport, C. America's Most Admired Corporations, "Fortune”, pp. 68-94, 30 January 1989.

Directive 2009/138/EU of the European Parliament and of the Council of 25 November 2009 on the taking-up and pursuit of the business of Insurance and Reinsurance (Solvency II).

Directive 2010/78/EU of the European Parliament and of the Council of 24 November 2010 amending Directives 98/26/EC, 2002/87/EC, 2003/6/EC, 2003/41/EC, 2003/71/EC, 2004/39/EC, 2004/109/EC, 2005/60/EC, 2006/48/EC, 2006/49/EC and 2009/65/EC in respect of the powers of the European Supervisory Authority (European Banking Authority), the European Supervisory Authority (European Insurance and Occupational Pensions Authority) and the European Supervisory Authority (European Securities and Markets Authority).

Dreher, M., Die Veröffentlichungspflichten von Versicherungsunternehmen gegenüber der BaFin, „Zeitschrift für die gesamte Versicherungswissenschaft” Vol. 98, No. 2, 2009.

Eichengreen, B. Origins and Responses to the Crisis. University of California, Berkeley, October 2008.

Forlicz, S. Niedoskonała wiedza podmiotów rynkowych [Imperfect Knowledge of Market Entities]. PWN, Warszawa, 2001.

Forlicz, S., Informacja w biznesie [Information in Business]. PWE, Warszawa, 2008.

Heise, M., Nach der Krise: Wirksame Regelungen auf dem Finanzmarkt?, „Wirtschaftsdienst“ Februar 2010. [https://www.allianz.com/ staticresources/de/ economic_research/ images_deutsch/pdf_downloads/ zeitungsartikel_und_interviews/zeitgespraech-feb10.pdf (12.04.2010)

IFRS, Conceptual Framework Phase A: Conceptual Framework for Financial Reporting: Objectives and qualitative characteristics of useful financial information; Issue 86 / October 2010; http://www.ey.com/Publication/vwLUAssets/Supplement_86_GL_IFRS/ \$File/Supplement_86_GL_IFRS.pdf

Izquierdo, S. S., Izquierdo, L. R., The Impact of Quality Uncertainty without Asymmetric Information on Market Efficiency, “Journal of Business Research” 2007/60 (8), pp. 858-867 
Jackowicz, K., Dyscyplina rynkowa $w$ bankowości. Rodzaje i możliwości zastosowania [Market Discipline in Banking. Application Types and Opportunities]. Wydawnictwo WSPiZ im. L. Koźmińskiego, Warszawa, 2004.

Jensen, M., Meckling, W., The Theory of the Firm Managerial Behavior, Agency Costs, and Ownership Structure, “Journal of Financial Economics” Vol. 3, No. 4, pp. 305-360, 1976.

Kraśniewska, I., Pawelec, D., Wypłacalność II - Własna Ocena Ryzyka i Wypłacalności - ORSA [Own Risk and Solvency Assessment - ORSA], PFSA - Departament Ubezpieczeniowego Nadzoru Finansowego [PFSA - Insurance Financial Supervision Department], $\quad$ Warszawa, $13 \quad$ October 2009. http://www.knf.gov.pl/Images/WII_wlasna_ocena_ryzyka_wyplacalnosci_ORSA_tcm7523598.pdf (18.02.2010)

Kurek, R. Jakościowe elementy nadzoru ubezpieczeniowego [Quality Components of Insurance Supervision] [in:] Handschke J. (ed.) Studia Ubezpieczeniowe [Insurance Studies], Zeszyty Naukowe Uniwersytetu Ekonomicznego w Poznaniu [Research Papers of the EU in Poznań] No. 127, pp. 75-82. Wydawnictwo UE w Poznaniu, Poznań 2010.

Kurek, R. (a) Prewencyjny charakter środków informacyjnych nadzoru państwowego a regulacyjna ocena działalności zakładów ubezpieczeń [Preventive Nature of State Supervision Information Means vs. Regulatory Assessment of Insurance Institutions Performance] [in:] Węcławski, J. (ed.), Karpuś, P. (ed. of vol.) Annales Universitatis Mariae Curie-Skłodowskae, Sectio H, OECONOMIA. Wydawnictwo UMCS, Lublin 2010.

Kurek, R. (b) Regulacyjna ocena działalności zakładów ubezpieczeń - elementy zwiększajace zakres i dostęp do informacji w ramach Solvency II [Regulatory Assessment of Insurance Institutions Performance - Elements Increasing Scope and Access to Information under Solvency II] [in:] Sokołowski, J., Sosnowski, M., Żabiński, A. (eds.) Polityka ekonomiczna [Economic Policy]. Prace Naukowe Uniwersytetu Ekonomicznego we Wrocławiu [Research Papers of the EU in Wroclaw] No. 111, pp. 338-351. Wydawnictwo Naukowe UE we Wrocławiu, Wrocław, 2010.

Marcinkowska, M., Ksztaltowanie wartości firmy [Establishing Company Vvalue]. PWN, Warszawa 2000.

Mas-Colell, A., Whinston, M. D., Green, J. R., Microeconomic Theory. Oxford University Press, New York 1995.

Mishkin, F. S., Ekonomika pieniqdza, bankowości i rynków finansowych [Economics of Money, Banking and Financial Markets]. PWN, Warszawa 2002.

Oleński, J. Infrastruktura informacyjna państwa $w$ globalnej gospodarce [Information Infrastructure of the State in Global Economy]. Uniwersytet Warszawski WNE, Warszawa 2006.

Polański, B., Pietrzak, Z., Woźniak, B., System finansowy w Polsce, tom I. PWN, Warszawa 2008.

Samuelson, P. A., Nordhaus, W. D. Ekonomia 2 [Economics 2]. PWN, Warszawa 1996.

Sloman, J., Podstawy ekonomii [Basics in Economics]. PWE, Warszawa 2001.

Sławiński, A., Makroekonomia a nadzór bankowy [Macroeconomics vs. Banking Supervision]. http://www.rp.pl/artykul/447653.html (16-03-2010). 
Spence, M., Job Market Signaling, “The Quarterly Journal of Economics”, 1973/87 (3), pp. 355-374.

Stiglitz, J. E., Informacja i zmiana paradygmatu $w$ ekonomii (część 1) [Information and Paradigm Change in Economics (part 1)]. „Gospodarka Narodowa” No.3, 2004.

Varian, H. R., Mikroekonomia [Microeconomics]. PWN, Warszawa 1997.

Weirich, P., Realistic Decision Theory - Rules for Nonideal Agents in Nonideal Circumstances. Oxford University Press, Oxford - New York, 2004.

Received: January 2012, revised: June 2013 